\title{
Interpreting the Protocol
}

\author{
STEPHEN WEATHERILL
}

\subsection{Introduction}

This chapter provides an overview of what the Protocol does and why it does it. This is a more challenging task than one might initially imagine because the Protocol is written with what one might generously describe as calculated ambiguity, or, less charitably, outright evasion. What the Protocol does is not what it says.

Elucidating its true meaning requires a journey through four particular matters: (i) identifying the customs territory to which Northern Ireland belongs, (ii) the effect on West to East (Northern Ireland to GB) trade, (iii) the effect on East to West (GB to Northern Ireland) trade, and (iv) state aid. Each of these issues is considered in greater detail in subsequent chapters. The argument of this chapter is that the approach to drafting the provisions of the Protocol is the same: in each case the Protocol is written in a way that understates the nature and the extent of the commitments made on the UK side.

The Protocol's resolution of all four issues has come under pressure as particular affected parties resist its full implications. Helpful adjustments have been made. The Protocol has been supplemented, first, by the Trade and Cooperation Agreement (TCA) which, by providing for tariff-free trade between the UK and the EU, reduces, but does not eliminate, the need for obstacles to intra-UK trade caused by divergent tariffs; second, by decisions taken by the Joint Committee (JC); and third, by adjustments in the form of unilateral declarations, some temporary, some permanent. ${ }^{1}$ Life under the Protocol has, however, been regrettably infected by a persisting disregard for and misrepresentation of its terms by members of the UK government.

${ }^{1}$ See https://ec.europa.eu/info/relations-united-kingdom/eu-uk-withdrawal-agreement /meetings-eu-uk-joint-and-specialised-committees-under-withdrawal-agreement_en. 


\subsection{Content of the Protocol}

The Protocol locks Northern Ireland (but not GB) into regulatory alignment with an extensive body of EU rules governing manufactured and agricultural goods. The detail is found in Annex 2 to the Protocol, to which deceptively brief reference is made in Protocol Article 5(4). Two hundred and eighty-seven EU legislative instruments are listed in Annex 2. The list is not static ${ }^{2}$ and it may be amended by the JC. ${ }^{3}$ Northern Ireland-EU alignment is extended by the Protocol also to cover trade rules concerning the EU's customs regime, ${ }^{4}$ value added tax (VAT) and excise rules, ${ }^{5}$ the single electricity market, ${ }^{6}$ and state aid rules in respect of measures which affect the trade between Northern Ireland and the EU which is subject to the Protocol. ${ }^{7}$ The Protocol also touches on particular aspects of individual rights to equal treatment, ${ }^{8}$ and the preservation of the Common Travel Area (CTA) covering the UK and Ireland. ${ }^{9}$ A series of Annexes contain intricate detail on exactly which EU measures are to be applied by the UK in Northern Ireland. Protocol Article 19 stipulates that 'Annexes 1 to 7 shall form an integral part of this Protocol'.

The application of these rules distinguishes Northern Ireland sharply from GB. This entails both changes in patterns of trade (because Northern Ireland products will be different from products made in GB and production and supply chains are likely to be disrupted) and the emergence of a customs and regulatory border between Northern Ireland and GB (because there has to be some kind of border between territories with divergent regulatory regimes). In so far as the UK chooses to diverge in GB from the EU model, those divisive issues will become ever more prominent over time. In short, then, in the areas covered by the Protocol, Northern Ireland is much more a part of the EU's internal market than it is part of the UK's internal market.

\subsection{Why the Protocol Exists}

Both sides, the EU and the UK, have made significant compromises in order to address what are recognized in the Protocol as 'the unique

2 Protocol Art 13(3).

${ }^{3}$ WA Art 164(5)(d) and Protocol Art 13(4).

${ }^{4}$ Protocol Art 5.

5 Protocol Art 8.

${ }^{6}$ Protocol Art 9.

7 Protocol Art 10.

${ }^{8}$ Protocol Art 2.

9 Protocol Art 3. 
circumstances on the island of Ireland'. ${ }^{10}$ The aim is to keep the border between Northern Ireland and Ireland as soft or invisible as it was immediately before the UK left the EU. This is a matter of economic significance, but much more so of political importance.

The EU has agreed three significant adjustments to its orthodox approach. It has agreed that: (i) its de jure external border, between Northern Ireland and Ireland, shall remain soft or invisible; (ii) its de facto external border, between Northern Ireland and GB, shall be located within the territory of, and policed by, a non-member state; and (iii) its economic freedoms in particular and its internal market legislative acquis in general shall be divided. In Northern Ireland an important package of EU rules shall be applied but not the whole of internal market law. ${ }^{11}$ The Treaty rules governing free movement of persons and services are not engaged; also excluded from the Protocol are legislative provisions on consumer and environmental protection which, though tied to the internal market by their legal base, do not directly address the composition of products. ${ }^{12}$

For its part, the UK, in order to maintain a soft or invisible border between Northern Ireland and Ireland and also to provide room for GB to pursue a different regulatory course from the EU, has accepted that the rules governing the matters covered by the Protocol will be different in Northern Ireland and in GB. This entails that the border between Northern Ireland and GB acquires a higher legal, economic and political significance than in the past. It is not an international border, but it now counts as a border between a jurisdiction, Northern Ireland, which shares the regulatory features mandated by the Protocol with the EU, and a jurisdiction, GB, which has largely (subject to discussion of state aid; see Section 6.7) separated itself from EU rules. That border, though in formal terms internal to the UK, must become harder than before. The Protocol thus represents a delicate balance which is the result of departures from orthodox approaches made on both sides.

Another way to understand this is to grasp that although the UK might have wanted three things - a soft border between Northern Ireland and Ireland; a soft border between Northern Ireland and GB; and the freedom to depart from the EU's regulatory model - it is not possible for the EU to

10 Protocol Art 1(3).

11 See S Weatherill, 'The Protocol on Ireland/ Northern Ireland: Protecting the EU's Internal Market at the Expense of the UK's' (2020) 45 European Law Review 222.

12 The Protocol's effect on environmental protection is examined in Chapter 20. 
accept all three, given the need to preserve the integrity of its internal market, which must be protected by an external border (somewhere). The UK can attain any two of those three objectives - but not all three. Prime Minister May's deal gave up the freedom to depart from the EU's regulatory model; Prime Minister Johnson's deal gave up the soft border between Northern Ireland and GB (albeit with the consequence that the regulatory freedom thereby released attaches to GB, not the whole of the UK). Looming in the future is the acute anxiety that, if the UK persists with its refusal to comply with the Protocol, the soft border between Northern Ireland and Ireland may have to be given up.

\subsection{Customs Territory}

The Protocol provides that de jure Northern Ireland is part of the UK customs territory. ${ }^{13}$ But the effect of the Protocol is that Northern Ireland is de facto part of the EU's customs territory for the purposes which are covered by the Protocol. This is the consequence of Article 5(3), which provides $^{14}$ that Northern Ireland is locked into the entirety of the EU's Customs Code, the Common Customs Tariff, legislation setting up a Union system of relief from customs duty, and international agreements containing customs provisions in so far as they are applicable in the EU (subject only to a reservation to the JC of the task of establishing the conditions applicable to certain fishery and aquaculture products), and several other customs-related measures, ${ }^{15}$ among them the EU's trade defence instruments covering, inter alia, anti-dumping and antisubsidy measures.

Several articles distant from the claim that Northern Ireland is part of the UK customs territory is Article 13(1). This confirms that this claim is in effect untrue, but does so in the spectacularly evasive terms which are the Protocol's hallmark. Article 13(1) declares that

any reference to the territory defined in Article 4 of Regulation (EU) No 952/2013 in the applicable provisions of the Withdrawal Agreement and of this Protocol, as well as in the provisions of Union law made applicable to and in the United Kingdom in respect of Northern Ireland by this Protocol, shall be read as including the part of the territory of the United Kingdom to which Regulation (EU) No 952/2013 applies by virtue of Article 5(3) of this Protocol.

\footnotetext{
${ }_{13}$ Protocol Art 4.

${ }^{14}$ Via Art 5 of the EU's Regulation 952/2013.

15 Via Protocol Art 5(4).
} 
What is 'the territory defined in Article 4 of Regulation (EU) No 952/ 2013'? It is the EU customs territory. What is 'the part of the territory of the United Kingdom to which Regulation (EU) No 952/2013 applies by virtue of Article 5(3) of this Protocol'? It is Northern Ireland. So although the Protocol says that Northern Ireland is part of the customs territory of the UK, that is not what it does. The Protocol treats Northern Ireland for most purposes as part of the EU's customs territory. Once it is appreciated that the Protocol contains misleading advertising, it is easier to understand.

\subsection{West-East Trade: Northern Ireland to GB}

Article 6 of the Protocol asserts that trade from Northern Ireland to GB shall be unfettered, and more generally it asserts an intent to protect the UK's internal market. But, again, the reality is different.

Article 6(2) of the Protocol directs the EU and the UK to 'use their best endeavours to facilitate the trade between Northern Ireland and other parts of the United Kingdom', but this is explicitly stated to occur 'in accordance with applicable legislation and taking into account their respective regulatory regimes as well as the implementation thereof. Article 6(2) directs that the JC shall adopt appropriate recommendations with a view to avoiding controls at the ports and airports of Northern Ireland - but only 'to the extent possible'. Neither, then, offers a basis for setting aside the obligations arising under the Protocol with regard to trade in goods from Northern Ireland to GB. And there are such obligations.

Article 5(3) of the Protocol requires that the normal formalities applicable to goods leaving the EU's customs territory shall apply to goods leaving Northern Ireland for GB. This entails that a pre-departure declaration be lodged, which shall take the form of a customs declaration, a re-export declaration or an exit summary declaration. ${ }^{16}$ Mitigation has occurred. In January 2021, the UK, in a unilateral declaration, announced that it would not require export and exit summary declarations. ${ }^{17}$ The EU took note and has accepted this. That acceptance is doubtless conditional on the provision of equivalent information through other means.

Article 6 also envisages impediments to trade between Northern Ireland and GB to the extent strictly required by any international

\footnotetext{
16 Pursuant to EU Regulation 952/2013.

17 See $n 1$ above.
} 
obligations of the Union' and requires that '[ $\mathrm{t}]$ he United Kingdom shall ensure full protection under international requirements and commitments that are relevant to the prohibitions and restrictions on the exportation of goods from the Union to third countries'. This entails checks to comply with the Convention on International Trade in Endangered Species of Wild Fauna and Flora (CITES). There are also special rules on movement of some cultural goods.

If the UK chooses to carry out no further checks on goods moving from Northern Ireland to GB, this would prevent it making a distinction between goods made in Northern Ireland and goods made in the EU which have been moved to Northern Ireland. Though not precluded by the Protocol, this would generate a risk of trade diversion in so far as the EU-Northern Ireland-GB route allows evasion of the customs and regulatory checks applied at other crossings from the EU into the UK. This does not seem sustainable.

Article 6 of the Protocol says that it is dedicated to protection of the UK internal market and that nothing shall prevent the UK from ensuring unfettered market access for goods moving from Northern Ireland to other parts of the UK's internal market. But that is not what the Protocol does. The Protocol entails that the border between Northern Ireland and GB shall acquire a higher legal, economic and political significance than it held in the past.

\subsection{East-West Trade: GB to Northern Ireland}

The Protocol does not suggest that trade in goods moving from GB to Northern Ireland will be unfettered. And it will not be.

Protocol Article 5(1) provides that no customs duties shall be payable for a good brought into Northern Ireland from another part of the UK by direct transport unless that good is at risk of subsequently being moved into the Union, whether by itself or forming part of another good following processing. So it seems that the norm is that no duties on GB to Northern Ireland trade are payable, while there is an exception where the good is at risk of onward movement to the EU when payment of duties is required. But this is not the case. Protocol Article 5(2) reverses the presumption by providing that a good brought into Northern Ireland from GB is considered to be at risk of subsequently being moved into the Union unless it is established that that good will not be subject to commercial processing in Northern Ireland and fulfils criteria to be established by the JC. The key point is that, under the Protocol, goods 
are deemed to be at risk of onward movement and so attract an obligation to pay duties, unless it is shown that they are not.

The starting point, then, is that duties are payable: in the matter of duties, exports from GB to Northern Ireland are treated in the same way as exports from GB to the EU generally. Exceptions foreseen by Article 5 Protocol are few and limited - for UK residents' personal property; for goods shown to be not at risk of onward movement in rebuttal of the presumption explained in the previous paragraph; for consignments of negligible value; for consignments sent by one individual to another; and for goods contained in travellers' personal baggage. There is also tightly drawn scope for reimbursing duties paid. This confirms that what the Protocol says is not what it does what it does is not treat Northern Ireland as part of the customs territory of the UK. It treats Northern Ireland as part of the EU's customs territory. Mitigation has occurred. The TCA has reduced the scale of the problem by securing tariff-free trade between the UK and the EU, with the consequence that tariffs are payable only on goods which do not qualify for such treatment under the Agreement, most obviously goods imported into GB from third countries. Moreover, in December 2020, the JC agreed criteria to determine when goods are not at risk of onward movement. ${ }^{18}$ The sharp edges of the Protocol have in this way been successfully softened, but not eliminated.

Obstacles to trade in goods between GB and Northern Ireland are not limited to payment of duties. The Protocol requires compliance with the obligations imposed by the EU Customs Code in matters such as entry summary declarations and customs declarations. It also requires that checks on goods be carried out in order to ensure that they comply with the EU rules which are applicable in Northern Ireland but not in GB. The full range of checks is not spelled out in the Protocol, in line with its thematic concern to avoid telling the full story about its extent. But compliance with EU rules on the many matters covered by the Protocol such as product composition, safety, technical standards and SPS requirements applicable to agricultural products and food will need to be checked according to the normal rules and procedures governing entry to the EU's territory, because GB will no longer be bound by these rules. Grasping the required intensity, location and nature of such checks, left undefined by the Protocol, will need reference sector-by-sector to applicable EU procedures in order to identify precisely what is at stake. ${ }^{19}$

18 Dec 4/2020 of the Joint Committee of 17 December 2020; see $\mathrm{n} 1$ above and Chapter 17.

19 The UK government's site is at www.gov.uk/government/collections/moving-goods-into -out-of-or-through-northern-ireland. 
The TCA does not change this because it does not include the type of regulatory alignment between the $\mathrm{UK}$ and the EU which would have permitted the EU to assume the compliance of GB goods with its rules. 'Grace' periods agreed by the two parties in 2021 were of only temporary effect. Looking forward, the greater the regulatory divergence that develops between GB and Northern Ireland, the greater the incentives to use the GB-Northern Ireland-Ireland trade route, and the more significant will the checks on GB to Northern Ireland trade in goods need to be.

In sum, the Protocol says that it protects the UK's internal market, but that is not what it does. It makes significant changes to it, especially, but not only, for GB to Northern Ireland trade in goods, and it establishes the Irish Sea as a politically, legally and economically significant frontier within it.

\subsection{State Aid}

The Protocol's treatment of state aid shares the deceptive character of several other provisions, but its geographical reach is considerably wider. Article 10 of the Protocol, combined with Annex 5, locks control of aid covered by the Protocol into the wider network of control exercised across the territory of the twenty-seven member states. Article 10 catches measures where they 'affect that trade between Northern Ireland and the Union which is subject to this Protocol'. This is plainly inspired by Article 107 TFEU, the key EU Treaty provision, which subjects to control any aid granted by a member state which distorts or threatens to distort competition 'in so far as it affects trade between Member States'. It creates a jurisdictionally significant threshold. Aid which does not affect trade between member states is not subject to EU law and is instead a matter of purely national concern: in the same way, aid which does not affect trade between Northern Ireland and the EU is not subject to the Protocol and is instead purely a matter for the UK. However, in EU law the Court interprets this jurisdictionally significant threshold as low. ${ }^{20}$

The same applies to the Protocol. Article 10 Protocol is not limited to aid granted directly to firms based in Northern Ireland. It is much wider than that. Again, there is far more to it than the Protocol admits. Probably, the grant of aid to small manufacturers of goods in, say, Kent would not affect the trade between Northern Ireland and the EU which is subject to the Protocol, but the grant of aid to firms which are based in GB

20 Eg, Case C-518/13 Eventech Ltd ECLI:EU:C:2015:9. See Chapter 19. 
but have a presence in Northern Ireland is likely to fall within Article 10. Once aid is being used in the Northern Ireland market (even if mainly being used in GB), that may help the recipient to expand its activities into Ireland (and beyond), and it may deter Irish (or other EU) firms from entering the Northern Ireland market because any competitive advantage they enjoy is eroded by the aid provided by the UK. The effect on interstate trade which is jurisdictionally necessary to trigger the Protocol is then present. The larger the aid, the more likely it is to fall within the Protocol's scope. Such aid is not automatically unlawful, but it must be compatible with EU law. This entails supervision by the Commission according to the terms set by the Treaty and secondary legislation, ${ }^{21}$ and it engages also the role of the Court of Justice of the European Union (CJEU) and of national courts in the same way as under EU law generally.

The only exception is in Protocol Article 10(2), which carves out a limited exception applicable to the agricultural sector. This concession is stated to apply up to a maximum overall annual level of support to be determined by the JC, which was duly set in December $2020{ }^{22}$

\subsection{Enforcement}

Some parts of the Protocol are subject to the arbitration procedures established by the Withdrawal Agreement (WA), including the exceptional derogation in Protocol Article 16, but Protocol Articles 5 and 7 to 10 , which contain the trade rules considered earlier, are enforced by methods which are closely aligned to those which prevail under orthodox EU law and which applied generally throughout the period of UK membership of the EU. ${ }^{23}$ That means that those provisions of the Protocol are enforced through two distinct routes: through the supervisory jurisdiction conferred on the Commission backed up by the role of the CJEU; and through enforcement by private parties before national courts relying on (inter alia) the direct effect and primacy of EU law, which extends to the Protocol, embracing also the preliminary reference procedure.

Article 13(2) adds that 'the provisions of this Protocol referring to Union law or to concepts or provisions thereof shall in their

21 Especially but not only the Block Exemption Regulations.

22 Dec 5/2020 of the Joint Committee of 17 December 2020; see $n 1$ above.

23 Protocol Art 12. 
implementation and application be interpreted in conformity with the relevant case law of the Court of Justice of the European Union'. This Protocol-specific provision asserts a longer-term and firmer obligation of compliance with the case law of the CJEU than is imposed by Article 4(4) and (5) WA. Here, there is nothing deceptive about the Protocol. The split within the UK internal market is plain. EU law orthodoxy continues to prevail in Northern Ireland, but not (state aid aside) in GB.

\subsection{Conclusion}

Ever since the UK's 2016 vote to leave the EU was won on a promise of an undeliverable confection of benefits, it has been plain that the form that the withdrawal would ultimately take would always disappoint some, many or even all of those involved. So too with the Protocol. Just as nobody wanted this Brexit, nobody wanted this Protocol. The Protocol is the product of reluctant compromise on both sides.

The Protocol entails the creation of a customs and regulatory border between GB and Northern Ireland and, in the areas it covers, its effect is to locate Northern Ireland within the EU's rather than the UK's internal market. The EU has nervously agreed to outsource policing of its de facto external border to a third country, the UK, and has accepted the divisibility of its economic freedoms. This cannot fully satisfy all involved. Yet the problems are caused not by the Protocol but by Brexit itself. The Protocol represents the unavoidable post-Brexit choice among three objectives: no hard border between Northern Ireland and GB; no hard border between Northern Ireland and Ireland; and regulatory autonomy for the UK (or GB). Only two of these can be achieved.

The Protocol is, as explained, drafted in evasive terms, and the areas where clarity is lacking all underplay the extent of the UK's readiness to accept fragmentation of its own internal market. The Protocol belongs alongside the 1998 Agreement as a subtly written offer to all involved to accentuate the positive and live with the negative. It is a genuine attempt to address the unique circumstances arising on the island of Ireland. With goodwill and honesty, the disappointments could be minimized. Those conditions seem increasingly elusive.

In late 2020, the UK Internal Market Bill included provisions that would have directly contradicted the obligations accepted by the UK under the WA, including the Protocol. The UK government eventually backed down. But, in March 2021, it once again set a course in conflict 
with the terms of the Protocol by announcing unilateral derogations from its requirements. This provoked the EU to begin legal proceedings. ${ }^{24}$ British politicians, including the Prime Minister, continue routinely to deny the impact of the Protocol. ${ }^{25}$ In July 2021, the UK government published a Command Paper which showed shameless disdain for the terms of the deal carefully negotiated and agreed in late 2019 and which included several proposals to amend the Protocol which the UK government is fully aware are unacceptable to the EU. ${ }^{26}$ It seems painfully clear that the Protocol was a device to 'get Brexit done' as part of a strategy that secured a General Election victory in December 2019 and that the UK government sees no further value in it. The same people who campaigned for Brexit with no regard for its consequences on the island of Ireland are now, having agreed the Protocol, showing disregard for its terms. Can this end well? Only if London is somehow forced to take seriously its binding international obligations. That one needs to make such an observation emphasizes the scale of the reputational damage which this government is prepared to inflict on the UK.

${ }^{24}$ European Commission Press Release IP/21/1132, 15 March 2021. See Chapters 5 and 8 of this volume.

25 See S Weatherill, 'Will the United Kingdom Survive the United Kingdom Internal Market Act?' UKICE Working Paper 03/2021, https://ukandeu.ac.uk/working-paper/will-theunited-kingdom-survive-the-uk-internal-market-act/, pp 19-22.

${ }^{26}$ Northern Ireland Protocol: The Way Forward (CP 502). 